\title{
National Union of Scientific Workers.
}

THE proceedings at the annual Council meeting of the National Union of Scientific Workers, held at the Imperial College of Science on January 26 , were enlivened by a spirited discussion on the position of the general secretary, Major A. G. Church, now that he has been elected member of Parliament for Leyton (East). The suggestion was made that his personal association with a political party might give the Union a political complexion, but the majority of the representatives present were evidently of the opinion that the more scientific workers there were in Parliament, irrespective of party, the more likelihood there would be of science exercising its proper influence in national affairs.

Mr. F. T. Brooks (Cambridge), in presenting the sixth annual report, emphasised the need for more propaganda among leaders of industry and public bodies in order that the importance of science to the nation should be more fully appreciated. During the year, a number of public meetings were arranged in different centres of industry, presided over by representatives of Chambers of Commerce and other public men. A questionnaire had been addressed to all members of the last Parliament with the view of ascertaining their attitude towards research and the public endowment of research institutions, and an offer had been made to certain industrial undertakings to put at their disposal the services of the Research Council, with the view of their making proposals for the proper utilisation of science in their industries. The fact is fully appreciated by the Executive of the Union that upon fuller recognition of the potentialities of science depends the welfare of the scientific workers who are being turned out from our universities yearly. It is hoped that the prominence given to this question at the forthcoming British Empire Exhibition at Wembley through the efforts of the British Science Guild will have far-reaching effects.

For the past two years at least, the claims made by the Union to the Treasury and other Government departments for the improvement of the salaries and conditions of service of scientific workers in Government departments have been weakened by the prevailing conditions of scientific workers in industry and in the universities. The attitude of the administrative heads of departments is demonstrated in the terms of the report of the committee on the pay of State servants. In this report it is stated that while the salaries of administrative officers cannot be based upon those which can be obtained by men of similar standing in outside professions, those of the scientific and technical officers were rightly based upon the current market rates. The Union will continue to press for a new inquiry into the position of civil servants engaged in scientific and technical work, and the setting up of the new Civil Service National Whitley Council, representation on both sides of which shall be confined mainly to scientific and technical officers. On the existing National Whitley Council, science has practically no voice, and to this fact can be attributed the want of success which has attended the efforts of the Union to obtain any measure of justice or equity of treatment.

Dame Helen Gwynne-Vaughan, the retiring president, in her address dealt with the need for a federation of scientific bodies with the view of the ultimate creation of a General Scientific Council similar to that of the General Medical Council; this would lead to the ideal of science as a self-governing profession.

Prof. G. H. Hardy, of Oxford, was elected president of the Union for the ensuing year, while Dr. J. W. Evans was unanimously elected president of the Research Council.

\section{Orographical Compensation in Northern India.}

A CONSIDERABLE discussion has arisen in A recent years regarding the precise meaning of the gravity variations revealed by the geodetic survey of India. The Himalayan region and bordering plains in the foreground, which are of special interest because of Archdeacon Pratt's mathematical development of the theory of mountain compensation, have formed the subject of revived discussion on account of the novel suggestion of subterranean rifting, made by Sir Sidney Burrard and his colleagues of the Indian Trigonometrical Survey and criticised by Mr. R. D. Oldham and the late Sir Henry Hayden of the Geological Survey. The geologists considered that insufficient allowance had been made for the low density of the large mass of alluvium in the foreground, and an analysis of the data by Mr. R. D. Oldham (Mem. Geol. Surv. Ind., xlii., part 2, I9I7) developed this aspect of the question as a partial explanation of the observed deficiency in gravity. Since I9I7, further data have been published by the Survey officers and by Prof. A. Alessio as the result of the Filippi expedition to Central Asia. These results have been examined by $\mathrm{Mr}$. R. D. Oldham in a paper recently published in the Records of the Geological Survey of India (vol. lv., part I, 1923), and he concludes that the fuller observations now available confirm the conclusions given in his previous memoir.

In one of the professional papers of the Survey of India (No. I8, I92I) Col. H. McCowie criticised Mr. Oldham's method of computation from an "imaginary range," but the method adopted was the only one possible without an organised computing staff with full topographical data, and the adoption of a simplified topography was frankly for the purpose of obtaining a sufficient approximation in results to estimate the relative values of the alternative theories. Other methods which have been criticised were similarly adopted in the absence at the time of data for a sufficient number of stations, and these, having now been supplied, permit of more precise computations being made.

Along the outer Himalaya there is a zone of superelevation where the defect of density, or compensation, corresponds to a lesser altitude than that of the surface, and along a parallel zone at the foot of the hills there is a region of over-depression of the surface, and consequently excessive deficiency of gravity. These two conditions, according to Mr. Oldham, can be sufficiently explained, when allowances are made for the rock densities, by assuming for the earth's crust a degree of rigidity which prevents it from taking up immediately and fully the flexures which followed the Himalayan uplift and coincident Gangetic depression.

A bye-product of Mr. Oldham's original line of argument was his conclusion that the excess of mass in the outer Himalayas would not continue over the whole range, but would disappear into the interior, and the results obtained during the course of the Filippi expedition to Central Asia seem to show that this is so.

$$
\text { NO. } 2832 \text {, VOL. I I } 3]
$$

